\title{
Assessment of the efficacy of electrical vestibular nerve stimulation as an adjunct therapy in the management of motor functions and quality of life in patients with Parkinson's disease
}

\author{
Sai Sailesh Kumar G1 ${ }^{1}$, Gawarikar $\mathbf{S}^{2}$, Anita Choudhary ${ }^{3}$, Potey GG ${ }^{4}$, Manju Purohit ${ }^{5}$, \\ Ashish Pathak ${ }^{6}$, Rohit Singh Chouhan ${ }^{7}$, Mahadik VK ${ }^{8}$ \\ ${ }^{1}$ Associate Professor, ${ }^{3}$ Professor and Head, ${ }^{7}$ Junior Research Fellow, Department of Physiology, ${ }^{2}$ Professor, \\ Department of General Medicine, ${ }^{4}$ Professor and Head, Department of Biochemistry, ${ }^{5}$ Professor and Head, \\ Department of Pathology, ${ }^{6}$ Professor, Department of Pediatrics, ${ }^{8}$ Medical Director, R.D. Gardi Medical College, Ujjain, \\ Madhya Pradesh, India
}

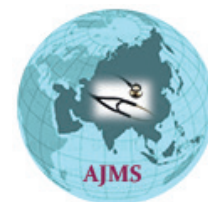

A B S T R A C T

Background: The existing treatments for Parkinson's disease (PD) were associated with side effects and do not offer a complete cure. Hence, there is a need for an alternative therapy that can prevent or delay the onset of PD with less or no side effects. Our extensive review of literature has shown no studies to be existing so far in India regarding vestibular stimulation as a treatment method for PD. Aims and Objectives: The present study was undertaken to administer electrical vestibular nerve stimulation (VeNs) as an adjunct therapy in the management of motor functions and to improve the quality of life in PD patients. Materials and Methods: The present study was a randomized controlled trial. (ClinicalTrials. gov Identifier: NCT04450550). 30 cases of PD, of both genders, were part of the study by convenient sampling after obtaining written informed consent. Patients were recruited from the out-patient ward of the General Medicine department, R.D. Gardi Medical College. Motor activities were assessed using the Berg balance scale, strength procedures by hand dynamometer and hand-eye coordination by 100 pin dexterity test. Quality of life was assessed by the World Health Organization Quality of Life Brief. Results: The study results support the earlier studies as there was a significant improvement in the motor functions and quality of life of the study participants. Conclusion: The study recommends further detailed studies with higher sample size and involving many centers to recommend the use of electrical VeNs as adjunctive therapy in the management of PD.

Key words: Electrical vestibular nerve stimulation; Motor responses; Parkinson's disease; Quality of life

\section{Access this article online}

Website:

http://nepjol.info/index.php/AJMS DOI: 10.3126/ajms.v13i3.42237

E-ISSN: 2091-0576

P-ISSN: 2467-9100

Copyright (c) 2022 Asian Journal of Medical Sciences

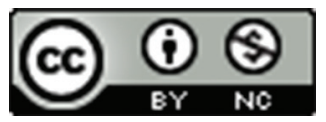

This work is licensed under a Creative Commons Attribution-NonCommercial 4.0 International License.

\section{INTRODUCTION}

Parkinson's disease (PD) is the second most common progressive neurodegenerative disease that occurs due to lack of dopamine. The diagnosis of PD is not easy as both motor and nonmotor symptoms should be assessed. At the same time, management is still a herculean task due to the limited availability of pharmacotherapies. The classical management of PD can be done by the administration of levodopa. ${ }^{1}$ The incidence of PD was reported to increase with the increase in age and the incidence was reported as 1 percentage in the elderly population about 65 years of age. ${ }^{2}$ The literature for the prevalence of PD in India is lacking. However, there are some regional studies that explained prevalence in a particular state. Loss of dopaminergic neurons in basal ganglia and accumulation of lewy bodies in cholinergic and monoaminergic neurons were reported to cause PD. ${ }^{3-6}$ However, apart from these areas many peripheral and central 
portions of the nervous system were reported to be involved in PD. ${ }^{7,8}$ As the basal ganglia output got distracted, it leads to the development of problems with gait and balance. ${ }^{9}$ Postural instability is the classical motor symptom to diagnose PD. ${ }^{10}$ A significant decline in postural stability was reported in PD patients. ${ }^{11}$ There is a strong need of alternative therapies that can help to improve the postural stability in PD patients. Vestibular stimulation was known to improve postural stability in elderly patients. ${ }^{12}$ The existing treatments for PD were associated with side effects and do not offer a complete cure. Hence, there is a need for an alternative therapy that can prevent or delay the onset of $\mathrm{PD}$ with less or no side effects. Our extensive review of literature has shown no studies to be existing so far in India regarding vestibular stimulation as a treatment method for PD.

\section{Aims and objectives}

The present study was undertaken to administer electrical vestibular nerve stimulation (VeNs) as an adjunct therapy in the management of motor functions and to improve the quality of life in PD patients.

\section{MATERIALS AND METHODS}

\section{Study design}

The present study was a randomized controlled trial. (ClinicalTrials.gov Identifier: NCT04450550).

\section{Study setting}

The present study was conducted at the Department of Physiology in collaboration with the Department of General Medicine of R.D. Gardi Medical College.

\section{Study participants}

Around 30 cases of PD, of both genders, were part of the study by convenient sampling after obtaining written informed consent. Patients were recruited from the outpatient ward of the General Medicine department, R.D. Gardi Medical College. Patients were randomly assigned to control and intervention groups with 15 participants in each group. The following criteria were used to recruit the participants.

\section{Inclusion criteria}

Willing male and female participants 18 years and older, who were in stage 1 and 2 Hoehn and Yahr Classification of Disability 79, 80, ambulate with or without an assistive device for at least 50 feet, we're able to get up and down from the floor with minimal assistance or less and score of 24 or above on the Folstein Mini-Mental State Exam were included in the study.

\section{Exclusion criteria}

Participants with declined immune functions, Progressive degenerative disease besides PD, spinal fusion or other orthopedic surgery in the past six months, mental disease/ psychosis such as dementia, greater than minimal assistance required for gait and transfers, inability to make regular time commitments to the scheduled intervention sessions, experience with regular practice of any form of vestibular stimulation within the past year were excluded from the study.

After recruiting, the participants were randomly assigned into two groups.

- Group 1: Control group ( $\mathrm{n}=15)$ : Placebo stimulation was administered for 12 weeks

- Group 2: Intervention group ( $\mathrm{n}=15)$ : Electrical vestibular stimulation was administered for 12 weeks.

\section{Electrical VeNs}

Bilateral electrical VeNs was administered using a battery-powered vestibular nerve stimulator (ML 1000, Neurovalens, UK). The total duration of the intervention is 12 weeks with 5 sessions per week. Each session duration is one hour. Sham stimulation was administered to the participants of the control group with identical devices. ${ }^{13}$

\section{Outcome measures}

\section{Berg balance scale (BBS)}

The 14-item scale is scored by the assessor. Postural stability was be assessed using the BBS. It assesses the ability of the individual to balance during a series of predetermined tasks safely. The BBS is a qualitative measure that assesses balance via performing functional activities such as reaching, bending, transferring, and standing that incorporates most components of postural control: sitting and transferring safely between chairs; standing with feet apart, feet together, in single-leg stance, and feet in the tandem Romberg position with eyes open or closed; reaching and stooping down to pick something off the floor. Each item is scored along a 5-point scale, ranging from 0 to 4 , each grade with well-established criteria. Zero indicates the lowest level of function and 4 the highest level of function. The total score ranges from 0 to $56 .{ }^{14}$

\section{Strength procedures}

Strength will be measured using the qingfeng handheld dynamometer. It was made up of ABS resin and a highquality spring. The unit of scale is $\mathrm{kg}$.

\section{Assessment of hand-eye coordination}

About 100 pins dexterity test was performed to assess the speed of coordinated movements. The test requires a smooth plastic pad containing fine pierceable 100 holes in it and 100 push pins. This set is provided to each participant and is assigned with a task to pin all 100 push pins to the pad. The time required to complete the task will be recorded using a stopwatch. The value will be expressed in seconds. 


\section{Assessment of quality of life}

Quality of life was assessed using the World Health Organization quality of life brief (WHO QOL-BREF) version. Prior permission from WHO will be obtained before using the same in the study. WHO-QOL BREF is a self-administered questionnaire that consists of 26 questions to assess four domains that are physical health, psychological status, social relationships, and environment. The participants were requested to assess their quality of life past two weeks on a five-point Likert scale. Raw scores of each domain are calculated by using the formulas provided along with the questionnaire. Raw scores will be converted into transformed scores between 0 and 100 ranges using the templates provided along with the questionnaire. Higher scores indicate higher quality of life. ${ }^{15,16}$

\section{Ethical considerations}

The study protocol was approved by the Institutional Human Ethical Committee of R.D. Gardi Medical College. (IEC Ref. N0- 124/2019).

\section{Statistical analysis}

Data were analyzed using SPSS 20.0. One-way analysis of variance followed by the Tukey HSD test was applied to observe the significance of the difference. A probability value $<0.05$ was considered significant.

\section{RESULTS}

Data were presented in Tables 1 and 2. There was a significant decrease in the time required for the 100 pin test, which indicates an improvement in the motor response in the intervention group (Table 1). No significant change was observed in the 100 pin test score in the control group. Significant improvement in the BBS score was observed in the intervention group after the intervention whereas no significant change was observed in the control group. There was a significant improvement in the handgrip strength in the intervention group when compared with the control group (Table 1). Physical health domain score was significantly improved in the intervention group. Whereas there was no significant change was observed in the control group. The psychological domain score was significantly improved in the intervention group. Interestingly, the psychological domain was significantly improved in the control group also. This may be due to the placebo effect. No significant change was observed in the social relationship score in the intervention group. However, a significant improvement was observed in the control group. The environmental domain score was significantly improved in the intervention group. Interestingly, the environmental domain was significantly improved in the control group also (Table 2). This may be due to the placebo effect.

\section{DISCUSSION}

The present study administered electrical VeNs as an adjunct therapy in the management of motor functions and to improve quality of life in PD patients. There was a significant improvement in the motor response and quality of life in the intervention group followed by the intervention. It was reported that vestibular stimulation improves motor responses in patients with PD. ${ }^{17}$ Further, it was reported that in the children with attention deficit hyperactive disorder there was a significant improvement

Table 1: Motor functions and quality of life of the intervention group $(n=15)$

\begin{tabular}{lccccc}
\hline Parameter & Baseline & After $\mathbf{6}$ weeks & After 12 weeks & F value & P-value \\
\hline 100 pin test & $12.2 \pm 3.8$ & $8.7 \pm 2.3$ & $7.8 \pm 2.1$ & 9.53 & $0.000383^{\star * *}$ \\
Berg balance scale & $27.7 \pm 9.5$ & $36.7 \pm 7.4$ & $40.93 \pm 7.2$ & 10.26 & $0.000234^{* * *}$ \\
Handgrip strength & $8.8 \pm 2.9$ & $11.6 \pm 3.3$ & $14.7 \pm 4$ & 10.94924 & $0.000149^{* * *}$ \\
Physical health domain & $46 \pm 8.3$ & $61.8 \pm 7.5$ & $64.8 \pm 8$ & 24.06472 & $<0.00001^{* * *}$ \\
Psychological domain & $43.3 \pm 6$ & $54.6 \pm 8.3$ & $59.5 \pm 9.2$ & 15.9171 & $<0.00001^{* * *}$ \\
Social relationship domain & $47.6 \pm 7.4$ & $48.4 \pm 4.2$ & $47.6 \pm 4.4$ & 0.10332 & 0.902066. \\
Environmental domain & $43.8 \pm 7.4$ & $59.8 \pm 8.2$ & $64.3 \pm 8$ & 27.58027 & $<0.00001^{* * *}$ \\
\hline$* * \star P<0.001$ is significant & & & & &
\end{tabular}

Table 2: Motor functions and quality of life of the control group $(n=15)$

\begin{tabular}{|c|c|c|c|c|c|}
\hline Parameter & Baseline & After 6 weeks & After 12 weeks & F value & P-value \\
\hline 100 pin test & $11 \pm 3.6$ & $10.2 \pm 3.8$ & $10 \pm 3.8$ & 0.26696 & 0.766991 \\
\hline Berg balance scale & $27 \pm 8 ., 15$ & $30.3 \pm 6.6$ & $31.1 \pm 6.3$ & 1.38061 & 0.2626 \\
\hline Hand grip strength & $8.0 \pm 3.9$ & $8.7 \pm 5.6$ & $9.6 \pm 5.2$ & 0.35485 & 0.703363 \\
\hline Physical health domain & $48.4 \pm 9.8$ & $42.6 \pm 12.3$ & $48 \pm 11.6$ & 1.20895 & 0.308684 \\
\hline Psychological domain & $41 \pm 6.6$ & $41.6 \pm 9.9$ & $48.4 \pm 8.9$ & 3.37613 & $0.043686^{*}$ \\
\hline Social relationship domain & $45.4 \pm 7.9$ & $36.2 \pm 12.3$ & $34.6 \pm 15$ & 3.49139 & $0.039566^{*}$ \\
\hline Environmental domain & $41.4 \pm 8.0$ & $35.3 \pm 10.1$ & $30.9 \pm 13.6$ & 3.51106 & $0.038905^{*}$ \\
\hline
\end{tabular}


in motor planning, attention, and balance. Vestibular stimulation was reported to improve multi-sensory processing. ${ }^{18,19}$ Vestibular stimulation was known to improve postural stability in the elderly population. ${ }^{20,21} \mathrm{It}$ was reported that there will be the integration of vestibular signals with the signals from other sensory systems and helps to maintain postural stability. ${ }^{22,23}$

The vestibular system was shown its integration with the midbrain, medulla, and spinal cord to maintain the postural balance. ${ }^{24-26}$

In bio-behavioral research, one of the well-accepted outcome measures is the quality of life. ${ }^{27}$ It was testified that quality of life is a reliable measure for testing any intervention effectiveness. ${ }^{28}$ Especially the non-motor symptoms of PD deteriorate the quality of life of the patients. These include lack of sleep and altered appetite and psychological distress. ${ }^{29}$ Vestibular stimulation was reported to increase physical fitness by increasing the muscular activity of both upper and lower extremities. ${ }^{30,31}$ Another possible way that vestibular stimulation increases physical health is by offering a relaxing effect and increasing sleep. ${ }^{32}$ Psychological wellbeing is improved by increasing blood flow to the brain, increasing brain metabolism, influencing the frontal cortex, and increasing the secretion of acetylcholine in the brain. ${ }^{33-35}$ Vestibular stimulation modulates mood and behavior through its connections with cortisol and subcortical structures and improves social relationships. ${ }^{36,37}$ By increasing the physical, psychological and social relationships domains, it increases the environmental domain also.

\section{Limitations of the study}

This initial pilot study has provided valuable insights into the use of vestibilar nerve stimulation for the use of pain management, however, further studies with larger sample sizes are recommended.

\section{CONCLUSION}

The study results support the earlier studies as there was a significant improvement in the motor functions and quality of life of the study participants. The study recommends further detailed studies with higher sample size and involving many centers to recommend the use of electrical VeNs as adjunctive therapy in the management of PD.

\section{ACKNOWLEDGMENT}

The study was funded by the Indian Council of Medical Research (2020-1352) (sanction letter 5/3/8/50/2020ITR). Our sincere thanks to Dr. Jason McKeown, CEO of Neurovalens for providing the electrical vestibular nerve stimulators to our study. We also thank all the participants of the study for their support throughout the study. Special thanks to our Dean, R.D.Gardi Medical College for providing all required resources to accomplish the study.

\section{REFERENCES}

1. Radhakrishnan DM and Goyal V. Parkinson's disease: A review. Neurol India. 2018;66 Suppl S1:26-35.

https://doi.org/10.4103/0028-3886.226451

2. Goldman SM and Tanner C. Etiology of Parkinson's disease. In: Jankovic J and Tolosa E, editors. Parkinson's Disease and Movement Disorders. $3^{\text {rd }}$ ed. Baltimore, MD: Lippincott-Williams and Wilkins; 1998. p. 133-158.

https://doi.org/10.1016/s0733-8619(05)70259-0

3. Razdan S, Kaul RL, Motta A, Kaul S and Bhatt RK. Prevalence and pattern of major neurological disorders in rural Kashmir (India) in 1986. Neuroepidemiology. 1994;13(3):113-119.

https://doi.org/10.1159/000110368

4. Devi MG, Gururaj $P$ and Satishchandra P. Bangalore Urban and Rural Neurological Survey. Report Submitted to the Indian Council of Medical Research; 1995.

https://doi.org/10.1159/000080090

5. Das SK and Sanyal K. Neuroepidemiology of major neurological disorders in rural Bengal. Neurol India. 1996;49:47-58.

6. Bharucha NE, Bharucha EP, Bharucha AE, Bhise AV and Schoenberg BS. Prevalence of Parkinson's disease in the Parsi community of Bombay, India. Arch Neurol. 1988;45(12):1321-1323. https://doi.org/10.1001/archneur.1988.00520360039008

7. Dickson DW, Braak H, Duda JE, Duyckaerts C, Gasser T, Halliday GM, et al. Neuropathological assessment of Parkinson's disease: Refining the diagnostic criteria. Lancet Neurol. 2009;8(12):1150-1157.

https://doi.org/10.1016/s1474-4422(09)70238-8

8. Halliday GM and McCann $\mathrm{H}$. The progression of pathology in Parkinson's disease. Ann NY Acad Sci. 2010;1184:188-195. https://doi.org/10.1111/j.1749-6632.2009.05118.x

9. Windels F, Thevathasan W, Silburn $P$ and Sah P. Where and what is the PPN and what is its role in locomotion? Brain. 2015;138:1133-1134.

https://doi.org/10.3389/fneur.2019.00410

10. Hughes AJ, Daniel SE, Kilford L and Lees AJ. Accuracy of clinical diagnosis of idiopathic Parkinson's disease. A clinicopathological study of 100 cases. J Neurol Neurosurg Psychiatry. 1992;55(3):181-184.

https://doi.org/10.1136/jnnp.55.3.181

11. Doná F, Aquino CC, Gazzola JM, Borges V, Silva SM, Ganança FF, et al. Changes in postural control in patients with Parkinson's disease: A posturographic study. Physiotherapy. 2016;102(3):272-279.

https://doi.org/10.1016/j.physio.2015.08.009

12. Rani S, Archana R and Kumar SK. Vestibular modulation of postural stability: An update. Biomed Res. 2018;29(17):3385-3388.

13. Goothy SS and McKeown J. Modulation of sleep using electrical vestibular nerve stimulation prior to sleep onset: A pilot study. J Basic Clin Physiol Pharmacol. 2020;32(2):19-23. https://doi.org/10.1515/jbcpp-2020-0019

14. Berg K, Wood-Dauphinee S, Williams JI and Gayton D. Measuring balance in the elderly: Preliminary development of an instrument. Physiother Canada. 1989;41:304-311. 
https://doi.org/10.3138/ptc.41.6.304

15. The World Health Organization quality of life assessment (WHOQOL): Position paper from the World Health Organization. Soc Sci Med. 1995;41(10):1403-1409. https://doi.org/10.1016/0277-9536(95)00112-k

16. Development of the World Health Organization WHOQOL-BREF quality of life assessment. The WHOQOL group. Psychol Med. 1998;28(3):551-558.

https://doi.org/10.1017/s0033291798006667

17. Yamamoto $Y$, Struzik ZR, Soma R, Ohashi K and Kwak S. Noisy vestibular stimulation improves autonomic and motor responsiveness in central neurodegenerative disorders. Ann Neurol. 2005;58(2):175-181.

https://doi.org/10.1002/ana.20574

18. Gori M. Multisensory integration and calibration in children and adults with and without sensory and motor disabilities. Multisens Res. 2015;28(1-2):71-99.

https://doi.org/10.1163/22134808-00002478

19. Stevenson RA, Baum SH, Segers M, Ferber S, Barense MD and Wallace MT. Multisensory speech perception in autism spectrum disorder: From phoneme to whole-word perception. Autism Res. 2017;10(7):1280-1290.

https://doi.org/10.1002/aur.1776

20. Badke M, Shea T and Miedaner J. Outcomes after rehabilitation for adults with balance dysfunction. Arch Phys Med Rehabil. 2004;85(3):227-233.

https://doi.org/10.1016/j.apmr.2003.06.006

21. Wrisley DM, Stephens MJ and Mosley S. Learning effects of repetitive administrations of the sensory organization test in healthy young adults. Arch Phys Med Rehabil. 2007;88(8):1049-1054. https://doi.org/10.1097/MAO.0000000000002950

22. Massion J. Postural control system. Curr Opin Neurobiol. 1994;4(6):877-887.

https://doi.org/10.1016/0959-4388(94)90137-6

23. Cenciarini $M$ and Peterka RJ. Stimulus-dependent changes in the vestibular contribution to human postural control. J Neurophysiol. 2006;95(5):2733-2750. https://doi.org/10.1152/jn.00856.2004

24. Keshner EA, Cohen H. Current concepts of the vestibular system reviewed: 1 . The role of the vestibulospinal system in postural control. Am J Occupat Ther. 1989;43(5):320-330. https://doi.org/10.5014/ajot.43.5.320

25. Brody BA, Kinney HC, Kloman AS and Gilles FH. Sequence of central nervous system myelination in human infancy. I. An autopsy study of myelination. J Neuropathol Exp Neurol. 1987;46(3):283-301. https://doi.org/10.1097/00005072-198705000-00005
26. Balter SG, Stokroos RJ, Akkermans E and Kingma H. Habituation to galvanic vestibular stimulation for analysis of postural control abilities in gymnasts. Neurosci Lett. 2004;366(1):71-75. https://doi.org/10.1016/j.neulet.2004.05.015

27. King $C R$, Overview of quality of life and controversial issues. In: King C, Hinds P, editors. Quality of Life: From Nursing and Patient Perspectives. Boston: Jones and Bartlett; 1998. p. 23-34.

28. Sreedevi A, Cherkil S, Kuttikattu DS, Kamalamma L and Oldenburg B. Validation of WHOQOL-BREF in Malayalam and determinants of quality of life among people with Type 2 diabetes in Kerala, India. Asia Pac J Public Health. 2016;28 Suppl 1:62S-69S. https://doi.org/10.1177/1010539515605888

29. Somaiya M, Faye A, Kamath R and Kolpakwar S. Study of mechanisms of coping, resilience and quality of life in medical undergraduates. Indian J Soc Psychiatry. 2015;31(1-2):19. https://doi.org/10.4103/0971-9962.161995

30. Parashar A, Pattnaik M and Mohanty P. Effect of vestibular stimulation versus whole body vibration on standing balance in children with spastic diplegic cerebral palsy. J Nov Physiother. 2017;7:348.

31. McGeoch PD, McKeown J, Peterson $\mathrm{H}$ and Ramachandran VS. Modulation of Body Mass Composition using Vestibular Nerve Stimulation, bioRxiv; 2017. p. 087692. https://doi.org/ https://doi.org/10.1101/087692

32. Omlin X, Crivelli F, Heinicke L, Zaunseder S, Achermann P and Riener R. Effect of rocking movements on respiration. PLoS One. 2016;11(3):e0150581 https://doi.org/10.1371/journal.pone.0150581

33. Serrador JM, Schlegel TT, Black FO and Wood SJ. Vestibular effects on cerebral blood flow. BMC Neurosci. 2009;10:119. https://doi.org/10.1186/1471-2202-10-119

34. Shin JH, Kim YK, Kim HJ and Kim JS. Altered brain metabolism in vestibular migraine: Comparison of interictal and ictal findings. Cephalalgia. 2014;34(1):58-67. https://doi.org/10.1177/0333102413498940

35. Gerretsen P, Pothier DD, Falls C, Armstrong M, Balakumar T, Uchida $\mathrm{H}$, et al. Vestibular stimulation improves insight into illness in schizophrenia spectrum disorders. Psychiatry Res. 2017;251:333-341. https://doi.org/10.1016/j.psychres.2017.02.020

36. An SJ. The effects of vestibular stimulation on a child with hypotonic cerebral palsy. J Phys Ther Sci. 2015;27(4):1279-1282. https://doi.org/10.1589/jpts.27.1279

37. Deroualle D and Lopez C. Toward a vestibular contribution to social cognition. Front Integr Neurosci. 2014;8:16. https://doi.org/10.3389/fnint.2014.00016

\footnotetext{
Authors' Contributions:

SSKG-Concept and design of the study, data acquisition, interpreted the results, reviewed the literature and manuscript, and prepared first draft of manuscript, GS,AC,PGG- Statistical analysis and interpretation, MP,AP and RSC- data acquisition, preparation and editing of manuscript; and MVK- Reviewed the literature and manuscript.

Work attributed to:

R. D. Gardi Medical College, Ujjain, Madhya Pradesh - 456 001, India

Orcid ID:

Dr. Sai Sailesh Kumar G - (1) https://orcid.org/0000-0002-2578-6420

Source of Funding: The study was funded by the Indian Council of Medical Research (ICMR-2020-1352). The devices used in this study were provided by Neurovalens (Belfast, UK), Conflicts of Interest: None.
} 